\title{
Nanostructured Architectures on the Heater Surface at Nanofluids Boiling and Their Role in the Intensification of Heat Transfer
}

\author{
Bondarenko B.I., Moraru V.N. ${ }^{*}$, Sydorenko S.V., Komysh D.V., Khovavko A.I. \\ Gas Institute, National Academy of Sciences of Ukraine, Kiev
}

Copyright (C) 2016 by authors, all rights reserved. Authors agree that this article remains permanently open access under the terms of the Creative Commons Attribution License 4.0 International License

\begin{abstract}
A major problem of modern science and industry is intensification of a heat transfer. One of the most promising ways for its solution is use of nanofluids as heat carrier and coolant that is capable to operate at high specific heat fluxes. In the course of nanofluids boiling porous sediments of nanoparticles are formed on the heating surfaces and provide a stable nucleate boiling mode. Whereas the specific heat fluxes grow up to $300-400 \%$ compared with water there is observed a significant increase of heat transfer coefficients, which is probably associated with the increase of porosity, roughness and wettability of heating surface. In order to clarify this question we studied the process of nanostructures formation in the course of different nanofluids boiling on the surface of $\mathrm{Ni} / \mathrm{Cr}$ - heater. The morphology and topography of artificial coatings were studied and the results were compared with the values of the basic boiling parameters: specific heat flux and heat transfer coefficient. The conclusions based on experimental results are: maximum values of the specific heat flux and the heat transfer coefficient refer for nanofluids consisting of a mixture of nanoparticles with anisometric shape. While boiling process in on they are able to create nanostructures with the most developed surface roughness and porosity. Most likely, this is due to the highest density of nucleation sites and the area of heat transfer surface formed in these nanostructures.
\end{abstract}

Keywords Nanofluids, Nanoparticles, Porosity, Roughness, Specific Heat Flux, Heat Transfer Coefficient

\section{Introduction}

Commonly called "nanofluids" (NFs) are the new generations of heat transfer medium, containing the colloidal dispersion of nanoparticles (NPs) in usual liquids (water, ethylene glycol, oils, etc.) [1]. Due to their increased heat conductivity and abnormally high heat exchange at NFs boiling they are promising for cooling of different power equipment (nuclear reactors, etc). We investigated the phenomenon of intensification of heat transfer by forming a porous layer of nanoparticles deposited on the heating surface at nanofluids boiling. The essence of this phenomenon is that the formed layer initiates a sustainable bubble boiling regime, which provides for high specific heat fluxes (q) and heat transfer coefficients $(\alpha)$, significantly higher than similar values for distilled water. For example, the value of q at boiling of water-based NFs may increase by $300-400 \%$ compared to pure water and to achieve the value of $3-4 \cdot 10^{6} \mathrm{~W} / \mathrm{m}^{2}$, and the heat transfer coefficient $(\alpha)$ may exceed $45000 \mathrm{~W} / \mathrm{m}^{2} \mathrm{~K}$ [1]. Moreover, it was found [2] that forming of the porous layer on the heater surface can delay or eliminate the phenomenon of the boiling crisis, which may lead to burnout and breakdown of equipment. It is assumed that all these positive effects are associated with alteration of the nature of heat transfer surface (wettability and roughness) and that a namely the porous structure and properties of deposited layer greatly determine the thermal parameters which characterize heat transfer at NFs boiling.

The influence of heat surface wettability on intensity of heat transfer and critical heat flux (CHF) at boiling has been the subject of numerous studies. It is well known that the CHF decreases sharply on hydrophobic surfaces, while the hydrophilic surface produces higher heat-transfer coefficients, as well as higher values of CHF [4-12]. Recent advances in research of changing the surface energy of solids [5] have opened new opportunities to improve heat transfer during boiling by decreasing the contact angle of wetting at the expense of "Nanoscale Surface Modification Techniques", i.e. the creation of nanostructures on heating surfaces [6].

The existence of such a connection has been noticed by several other researchers. For example, Kim and Buongiorno 
with collaborators $[7,8,9]$ noted that at nucleate boiling NFs based on oxides of aluminum, zirconium and silicium some nanoparticles are deposited on the heating surface and form a porous layer, giving significant growth of CHF. They also proved that this layer significantly increases a wettability of a heating surface, which is confirmed by the decrease of the contact angle of wetting of the surface after NF boiling compared with surfaces after distilled water boiling. The decrease of a contact angle is associated with changes of surface energy and surface morphology caused by the presence of a nanoparticles layer. On the basis of existing theories of hot/dry spots [10] the authors [8,9] showed that there is the certain connection between an increasing of a $\mathrm{CHF}$ and an improving of wettability of the surface. The results of their estimates of the CHF growth as far as the contact angle of wetting is reduced are in good coherence with the values obtained in the experiment.

In another work of Pham et al. [11] on the example of water based NFs with $\mathrm{Al}_{2} \mathrm{O}_{3}$ nanoparticles and carbon nanotubes (CNTs) it has shown that for high values of CHF and the heat transfer coefficient at boiling it is not at all necessary to cover the surface of the heater by a continuous layer of nanoparticles and to have high wettability, although the latter is also important for heat transfer. A much more important parameter for intense heat exchange is a roughness of nanoparticles deposited layer on the heating surface. Although it is known [5], that the increase of roughness also improves wettability of the surfaces.

According to [11] in the case of the combined nanofluid $\left(\mathrm{Al}_{2} \mathrm{O}_{3}+\mathrm{CNTs}\right)$ both factors act simultaneously (improvement of wettability and increase of surface roughness) and this leads to the relative high CHF value. Analysis of data about CHF value obtained in this work shows that the higher the roughness the more CHF regardless of the contact angle.

Therefore, even if grows of the CHF at nanofluid boiling occurs due to contribution of both factors (wettability and surface roughness), the effect of roughness stronger and more dominant than the influence of the contact angle of wetting. This probably occurs because the increase in surface roughness of the heating raises not only the heat exchange area, but the density of the centers of vaporization.

Investigations have confirmed the importance of surface wettability improvement and formation of nanostructures on the heater's surface as an effective method to improve heat transfer during boiling process.

Over the last decade, a considerable number of studies have shown that for NFs the increased values (up to 10-35\%) of heat conductivity are characteristic in comparison with those for the base fluid (water, ethylene glycol) [3, 13-16], and that the use of NFs as heat transfer mediums allows to achieve high values of CHF and heat transfer coefficient at boiling [7-9, 17-20]. In spite of this, the mentioned increase of heat conductivity can't explain the anomalously high intensity of heat transfer (>200\%) at NFs boiling compared with water. Experiments have shown that the increased CHF and $\alpha_{\max }$ at NFs boiling are determined mainly by the state of the heating surface, its topological and chemical properties.

It is clarified that there is the relation between the intensity of heat transfer and the character of nanostructured deposits on the heating surfaces at NFs boiling. Therefore, we examined in detail porous structure and topography of deposits, studied boiling curves for different NFs and obtained results are compared to such important heat exchange parameters as $\mathrm{q}_{\mathrm{cr}}$ and $\alpha_{\max }$. On the ground of the analysis of experimental data (graphical dependencies, photo images including scanning electron microscope and others $[1,2])$ it was obtained the interesting information about the influence of the shape and nanoparticles anisometry on the surface microrelief and the intensity of heat exchange. Resulted data is important for practical application of NFs.

\section{Materials and Methods}

Objects of present research were aqueous nanofluids based on natural aluminosilicates from Ukrainian deposits attapulgite (AlSi-5), hydromica (AlSi-6) and a genetic mixture of montmorillonite and attapulgite (AlSi-7). Also the mixture of silicates and carbon nanotubes (AlSi-7+CNTs) was studied. For comparison it has been studied NF-based on water nanodispersion of titanium dioxide $\left(\mathrm{TiO}_{2}\right)$ of rutile modification with isometric particles form $(k=1 / d \approx 2-5)$ (see Table 1 ).

Nanofluids were prepared on installation UZDN-2T by a short $\left(2\right.$ min) ultrasonic dispersion of $\mathrm{Ca}^{2+} / \mathrm{Na}^{+}$and $\mathrm{Ca}^{2+} / \mathrm{Mg}^{2+}$ - forms of aluminosilicates powders in distilled water without dispersant application.

The dispersion composition and $\zeta$-potential of NFs were determined by laser correlation spectrometer ZetaSizer NANO-ZS (Malvern Instrument, UK) and surface tension by Wilhelmy plate method (modified tensiometer K6 (KRÜSS GmbH, Germany). The stability of investigated NFs was evaluated both by their $\zeta$-potential and sedimentation and was quite satisfactory for the measurement of thermal parameters.

For the study of nanostructured deposits on the heating surfaces at NFs boiling we used porometer QuantaChrome ${ }^{\circledR}$ AsiQwin ${ }^{\mathrm{TM}}$ and scanning electron microscope JSM6700F.

Heat engineering experiments were performed by specially designed and fully automated test unit [3], equipped with DC power supply and operated by program enabling to control in real time by PC all the parameters of a critical mode including CHF. It includes investigation of heat exchange process while pool boiling with reaching of critical heat flux. Test unit scheme is presented on Fig. 1. 


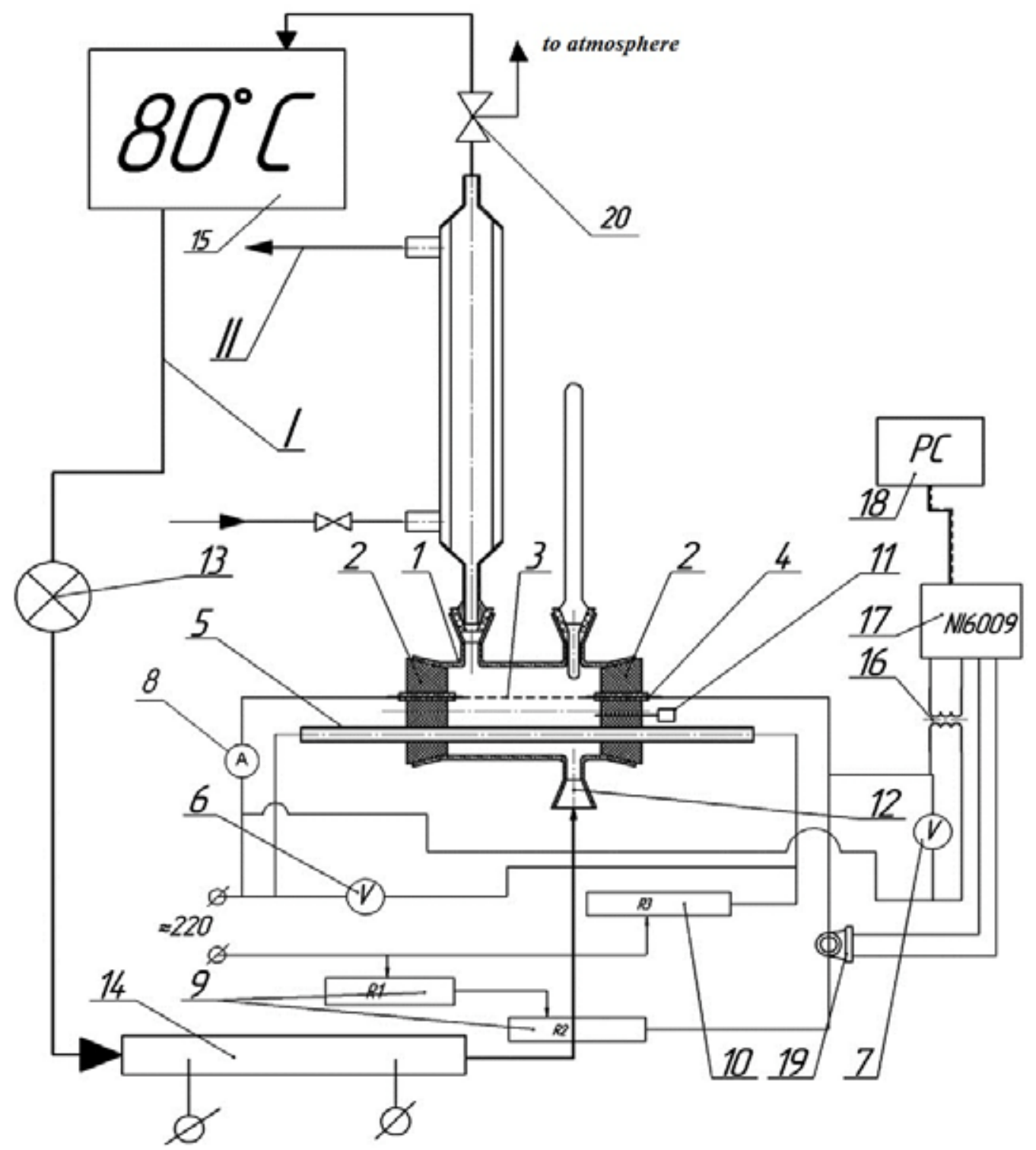

Figure 1. Scheme of the test unit. 1 - experimental reservoir; 2 - stopper; 3 - main heater; 4 - main heater bus; 5 - secondary heater; 6 - voltmeter for secondary heater; 7 - voltmeter for main heater; 8 - ammeter; 9 - rheostat for main heater; 10 - rheostat for secondary heater; 11 -thermocouple; 12 - down comer; 13 - circulating pump; 14 - additional heater; 15 - preheating reservoir; 16 - rheostat; 17 - NI-DAQmx USB-6009; 18 - PC; 19 - CSLA1CD; 20 T-joint. I - experimental fluid; II - cooling water.

Dependency of nichrome electrical resistance on its temperature was used to define heater outer surface temperature. All measurements of input and calculated parameters (voltage, current, critical heat flux, heat exchange coefficient etc.) were made with specially developed software. It was able to create graphical dependencies between them in real-time mode.

Method provides fluid boiling on a surface of the main heater, which is horizontally disposed nichrome wire $(0,31$ $\mathrm{mm}$ in a diameter and $143 \mathrm{~mm}$ in a length). Reaching of CHF is traced by real time graphs, which show us boiling curve for each experimental fluid during all process. Voltage control is provided with two rheostats connected by cascade scheme. It gives ability for very precise of voltage regulating and gradually draw near purposed amount of CHF.

The main reservoir has apertures for installing the heaters, thermometer, thermocouples and connections to circulating contour, since nanofluids are unopaque that under their boiling impossible to fix visually the achievement of the critical heat flux. For this purpose program of the computer calculation of the specific heat flux (SHF) and heat transfer coefficient (HTC) is designed for observation for change parameter of boiling in real-time mode.

The experimental procedure was as follows. Experimental vessel was filled by water or one of selected NFs. The working fluid was preheated by an auxiliary heater (500 W). Then, the main heater was turned on. Input power was automatically increased at a constant rate until the achieving of maximum SHF. Power supply was stopped after heater burnout. CHF measurement error did not exceed 1\%. Fluid samples were collected for measurement of surface tension, zeta-potential and $\mathrm{pH}$ in order to control the stability of $\mathrm{NF}$ before and after the experiment.

Described above test unit and experiment method are 
capable to define main heat transfer parameters as SHF $(q)$ and HTC $(\alpha)$. Well known equation is used:

$$
\alpha=q /\left(t_{w}-t_{f}\right),
$$

where $t_{w}-$ heater outer surface temperature, ${ }^{\circ} C$ (methodology of $t_{w}$ calculation is presented in the work [3]); $t_{f}$ - liquid boiling temperature, ${ }^{\circ} C$;

$$
q=Q / F=I U / F,
$$

where $Q$ - full heat load on the main heater, $W ; I$ - current, $A$; $U$ - voltage, $V$; $\mathrm{m}^{2}$;

$F=\pi d l$ - outer surface area of the heater (nichrome wire),

where $d, l$ - diameter and length of the nichrome wire accordingly, $\mathrm{m}$.

\section{Results and Discussion}

The mechanism of formation of nanostructures on boiling surfaces is much like the formation of scale on the heater surface, with the difference that in the first case there is the single-stage process, i.e. at nucleate boiling of NFs, NPs deposit on the surface near the centers of vaporization, whereas in the second case the process is multi-stage. First, in volume with temperature rise, the decomposition of the molecules of soluble bicarbonates of $\mathrm{Ca}, \mathrm{Mg}$, Fe and others are occurred then their condensation into larger particles of insoluble carbonates and then their deposition is taken place on the surface. In the first case there are more or less porous sediments, whereas in the second case there is a scale which has a dense structure with high thermal resistance, causing a sharp decrease of heat exchange intensity and as possible consequence - main heater burnout.

We have found that the particles deposition and formation of nanostructures on the heating surface has been observed already in the pre-crisis area of the nucleate boiling of NFs $\left(\mathrm{q}_{\mathrm{cr}}<0.7 \mathrm{MW} / \mathrm{m}^{2}\right)$, which dramatically changes the shape boiling curve and increases heat transfer coefficient.

Several factors are influenced for the boiling process and the nature of forming sediment. They are - a variety of electric current (DC or AC) as well as chemical nature, form and anisometry of nanoparticles etc.

Experimental study of heat transfer at boiling of aluminosilicate NFs showed that the type of applied electric current significantly affects to the sediment formed on the heater surface and as a consequence of that to the thermal parameters of NFs. So, for example, it was found that at boiling when unit operating at direct current, all aluminosilicate NFs show intensive nanoparticles deposition on a copper anode.

At the same time the sediment of nanoparticles (NPs) that formed around wire $\mathrm{Ni} / \mathrm{Cr}$-heater has a gel-like or porous structure. It has the shape of the cone directed by its base to the negative pole (cathode) (Fig.2a,b). This is probably due to the fact that the one part of negatively charged particles of the silicates discharge and form dense deposit on the anode. The other one deposited on the heater surface experience a growing repulsion, disintegrating (loosen) action and complete rejection as it approaches the negative pole. At the cathode and in the vicinity of it a precipitate is not formed or it is loosen by an electric field to such extent that aggregation of particles is eroded due to the turbulence caused by boiling.

Indeed, as it can be seen from Fig.2a,b,c, the sediment formed around the $\mathrm{Ni} / \mathrm{Cr}$-wire has sharply non-uniform thickness and in the vicinity of the negative pole it is not formed in general (Fig.2c). At the same time, when the heater works at AC mode, the sediments are more or less uniform in their thickness. They are distributed along the entire length of $\mathrm{Ni} / \mathrm{Cr}$ - wire, but not form a continuous coating. In this case the sediment thickness is much less (Fig.2d) as compared with that presented in the Fig.2a.

Accordingly, the value of $\mathrm{CHF}$ at AC is significantly higher than for DC. For example, for attapulgite nanofluids $\mathrm{CHF}$ values are in the intervals $3.1-4.0 \mathrm{MW} / \mathrm{m}^{2}$ and $1.6-$ $2.24 \mathrm{MW} / \mathrm{m}^{2}$ depending on nanoparticles concentration, for AC and DC, respectively. However, the ratios of CHF values for nanofluids and distilled water remains constant in the range of 2.1 - 3.0, both for AC and DC [1].
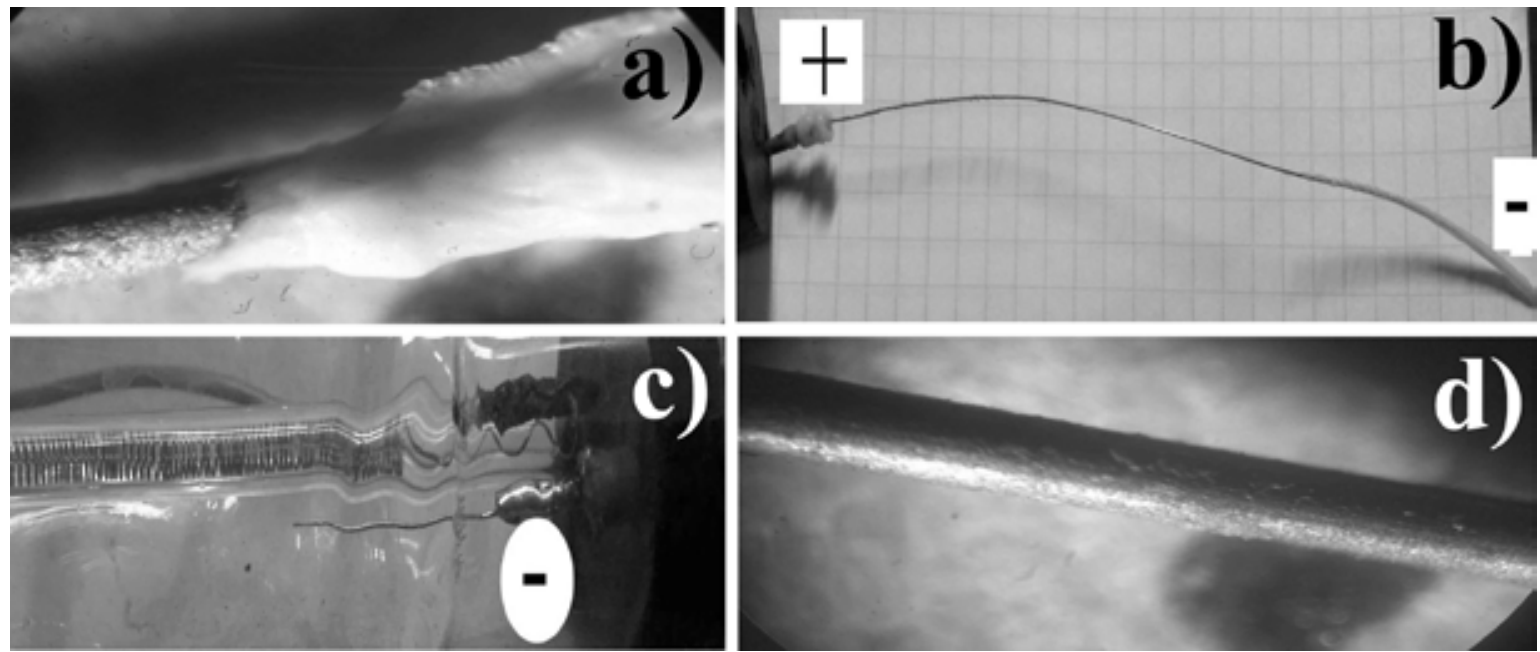

Figure 2. Photoimages of the heater after overburning. It is shown deposited porous gel-like layer of nanoparticles after boiling of AlSi-7 nanofluid at DC current (a,b), the anode side (b) and cathode (c) and after boiling AlSi-7 at AC (d). 
The observed difference in the nature of deposits on the surface of the heater at AC and DC operation is explained by the superposition on to process of nanofluids boiling the phenomena of electrophoresis and electrocoagulation of the nanoparticles. These phenomena are the result of direct influence of the electric field on the suspension, which is stronger at DC. The numerous experimental data suggest that the stable suspensions and emulsions can coagulate in presence of external electric field [21-23]. The phenomenon of electrocoagulation was theoretically interpreted as a non-equilibrium electrosurface phenomenon [24-26]. The mechanism of electrocoagulation is closely related with electrical properties of disperse systems and with presence of the electric double layers (EDL) around colloid particles. Under the influence of the tangential component of external electric field, the ions of particles in their EDL move along their surface forming an electrosurface current. The density of this current is proportional to the local value of the given constituent of the electric field. The induced dipole moment (IDM) formed under the influence of external electric field determines the polarization (electrocoagulation) interactions between particles. These interactions are important at the distances that may be several times larger as compared with the size of the particles [24-26].

For NFs with strongly hydrophilic particles (such as AlSi-5,6,7) this mechanism is realized at presence and maintaining of the structural barrier between particles. It can occur due to their fixation at a distant attractive well (secondary minimum) that became deeper due to the resulting dipole-dipole attractions. As a result, the sediments formed during the boiling around the heater have reversible gel-like structure (Fig.2b) and it transforms to the porous xerogel structure after the drying (Fig.2a). Such sediment can be easily removed during the regeneration of the equipment and it is one of the advantages of such NFs.

The electrochemical processes on the electrode, leading in particular to a significant change in value of $\mathrm{pH}$, can also facilitate the structure formation in the sediment on the heating surface. In this case, the neutralization of a charge of particles and their irreversible coagulation (by neutralization mechanism) in the primary minimum are possible [26]. The removal of the residue from the electrodes and the heat transfer surfaces is almost impossible for irreversible coagulation. It can be a big problem for regeneration of equipment.

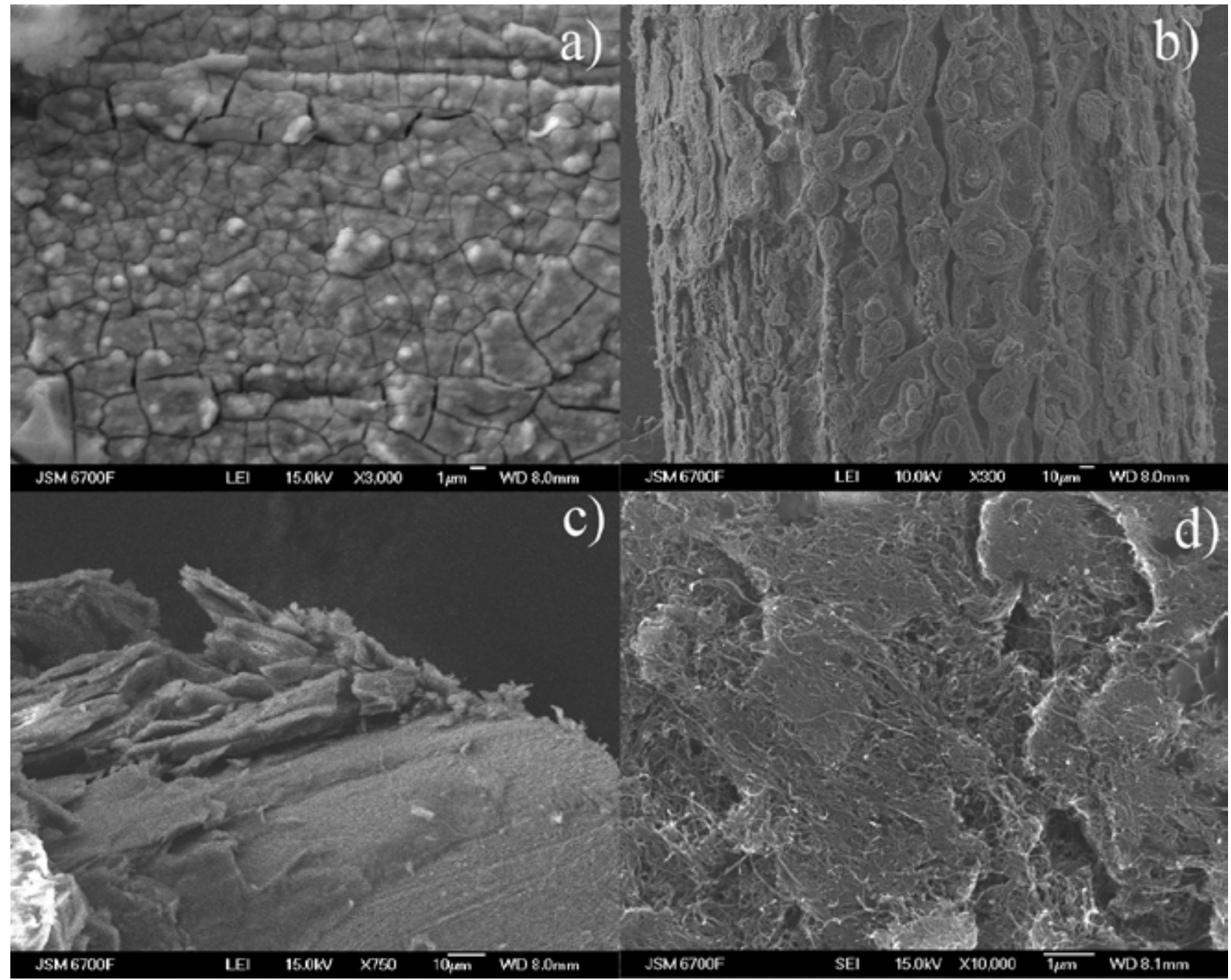

Figure 3. ESM-image of the sediments on the heating surface after boiling of wate nanofluids on the basis of: a) - hydromica, b) - $\mathrm{TiO}_{2}$, c) - the natural mixture of attapulgite and montmorillonite, d) - the same mixture with the addition of $0.2 \%$ of carbon nanotubes. 
Beside of polarization of the EDL in nanofluids, the electric field intensifies the transport of charged particles into the sediment due to the electrophoresis (DC) and dipolophoresis (AC) [26]. The impact of these phenomena on the process of NP deposition under the boiling of nanofluids can significantly change the character of sediment formation on the heating surface, which is supported by the values of the corresponding thermal parameters at NFs boiling (Table 1).

Now it is also clear that in addition to the type of applied electrical current (AC or DC) the process of sediment formation, the surface roughness and porous structure of the sediments can be influenced by the parameters of applied electric field (intensity, heterogeneity and frequency), properties of the particles (their size, shape, anisometry, charge and electrical conductivity), composition of the electrolyte, and other factors. All these factors in a line with particle hydrophilicity are important. They define the structure and wettability of porous boiling surface and as a consequence the heat transfer rate. For example, for anisometric particles the polarization interaction energy depends upon orientation of particles in electric field [26] and it allows regulation of micro/nano-reliefs and roughness of deposits. In general, the possibility of variation of different parameters and modes of process are rather wide. It allows affecting the "architecture" of nanostructured sediments and intensity of heat transfer during the boiling. These problems may be the subject of investigation in future.

Thus, it is established that the type of electric current (AC or DC) significantly affects to the structure of the sediment, which is formed on the heater surface at NFs boiling and as a result to the thermal parameters of aluminosilicate NFs.

Also, this paper presents materials about an impact of the topography of deposited NPs on the heating surface at NFs boiling to the character of the boiling curves and the intensity of heat exchange. It is obvious that the deposition of oxides and silicates particles on the metal heating surface make it more hydrophilic and rough, as evidenced by the decrease of the contact angle of wetting $\theta[7-9,11]$ and ESM images of the surface sediments (Fig. 3). While the increase in wettability and surface roughness, as it is known [8-10], increase $\mathrm{q}_{\mathrm{cr}}$ и $\alpha$.

As is known [27], the boiling crisis is not only a hydrodynamic phenomenon. This crisis can be result of the expansion of the hot/dry spots developed during the process boiling. That why these hydrophility and surface wettability of nanoparticles have an important role in delaying the boiling crisis. For this reason, the more stable (too long and repeated boiling-cooling processes and with higher thermal parameters) NF filled with hydrophilic particles as compared with NF filled with hydrophobic particles (Sulfur and Carbon Black DG-100) were developed [3]. The relationship between the value of CHF and the surface wettability of NPs was previously discussed in detail [7-9]. At the high heat flux the hot/dry spots on the heater surface develop within the bases of the bubbles growing at certain nucleation sites $[9,10,27]$. The hot/dry spots can be reversible or irreversible. In absence of rewetting they are irreversible. It causes the rapid increase of the temperature and consequently the effect of burnout. The formation of dry spots and their spreading was registered using the high speed video technique [28]. The presence of the nanoparticle layer on the heating surface can help delay the critical heat flux. It is due to the increase of the surface wettability after departure of the bubble.

Note that the vapour pressure in the centre of vapour formation drives the receding of liquid meniscus. From other hand the surface tension forces the contact line between phases to the minimum and drives the rewetting the hot/dry spots. It was postulated that CHF can occur when the vapour pressure exceed the surface tension force [9]. The following expression for the CHF was derived on the basis of these arguments:

$$
\left.\mathrm{q}_{\mathrm{cr}}=\kappa^{-1 / 2} \rho_{\mathrm{g}} \mathrm{h}_{\mathrm{fg}}\left[\sigma\left(\rho_{\mathrm{f}}-\rho_{\mathrm{g}}\right) \mathrm{g} / \rho_{\mathrm{g}}{ }^{2}\right)\right]^{1 / 4}
$$

Here $\sigma$ is surface tension; $\rho_{f}$ and $\rho_{g}$ are the densities of fluid and vapor respectively; $h_{f g}$ is the thickness of vapor layer near the heating surface.

Note that Eq. (3) and the traditional Kutateladze-Zuber's formula [29] are essentially the same except for the parameter $\kappa$. According to [8]

$$
\kappa=[(1-\sin \theta / 2)-(\pi / 2-\theta) / 2 \cos \theta)]^{-1 / 2}
$$

where $\theta$ is a contact angle (rad).

The values of $\kappa$ for $\theta \sim 70^{\circ}$ (clean surface) and $\theta \sim 20^{\circ}$ (nanoparticle-fouled surface) are about 7.1 and 2.36, respectively.

The substitution of these parameters to the Eq. (3) gives increase in the CHF value by a factor of $\sqrt{7,10 / 2,36} \sim 1.73$ or $73 \%$. However, the introduction of the $\kappa$ only accounts the steady state interaction of heat medium and heating surface and does not accounts for the density of evaporation centers, own roughness of the surface, impact of NPs on the thermal conductivity and viscosity of NF.

The recent calculations of the density and diameter of nucleation centers on modified surface ( $\mathrm{Cu}$ created by an electrodeposition technique) revealed a direct link between these factors and the heat transfer coefficient (HTC) and CHF [30]. 

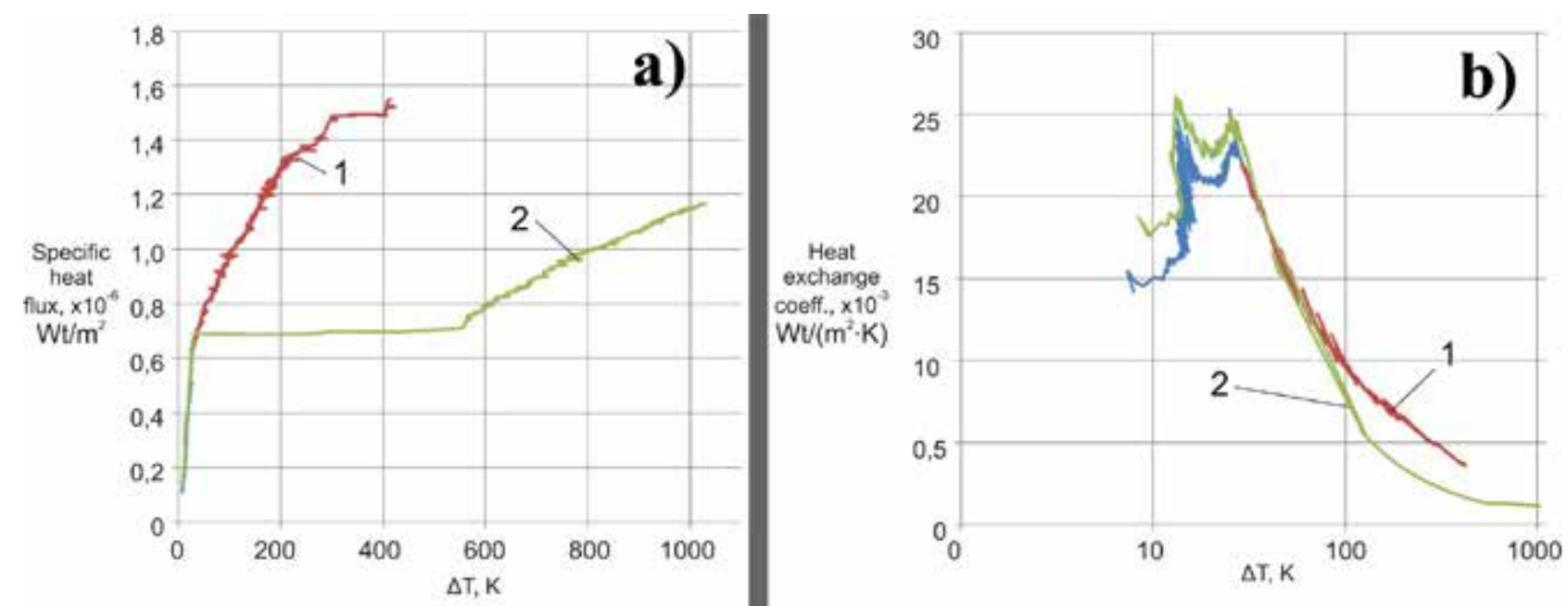

Figure 4. Boiling curves (a) and heat exchange coefficient as a function of surface superheat value ( $\Delta \mathrm{T})$ (b) for hydromica based nanofluid (1) and distilled water (2)
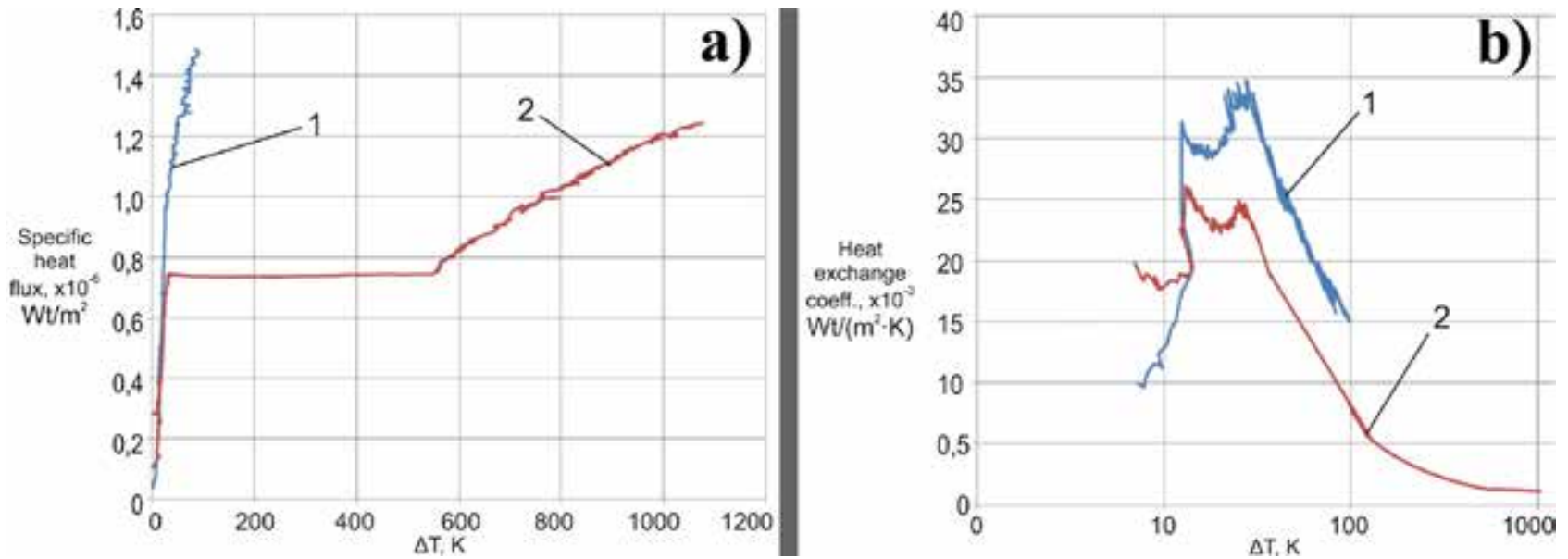

Figure 5. Boiling curves (a) and heat exchange coefficient as a function of surface superheat value ( $\Delta \mathrm{T})$ (b) for $\mathrm{TiO}_{2}$ based nanofluid (1) and distilled water (2)
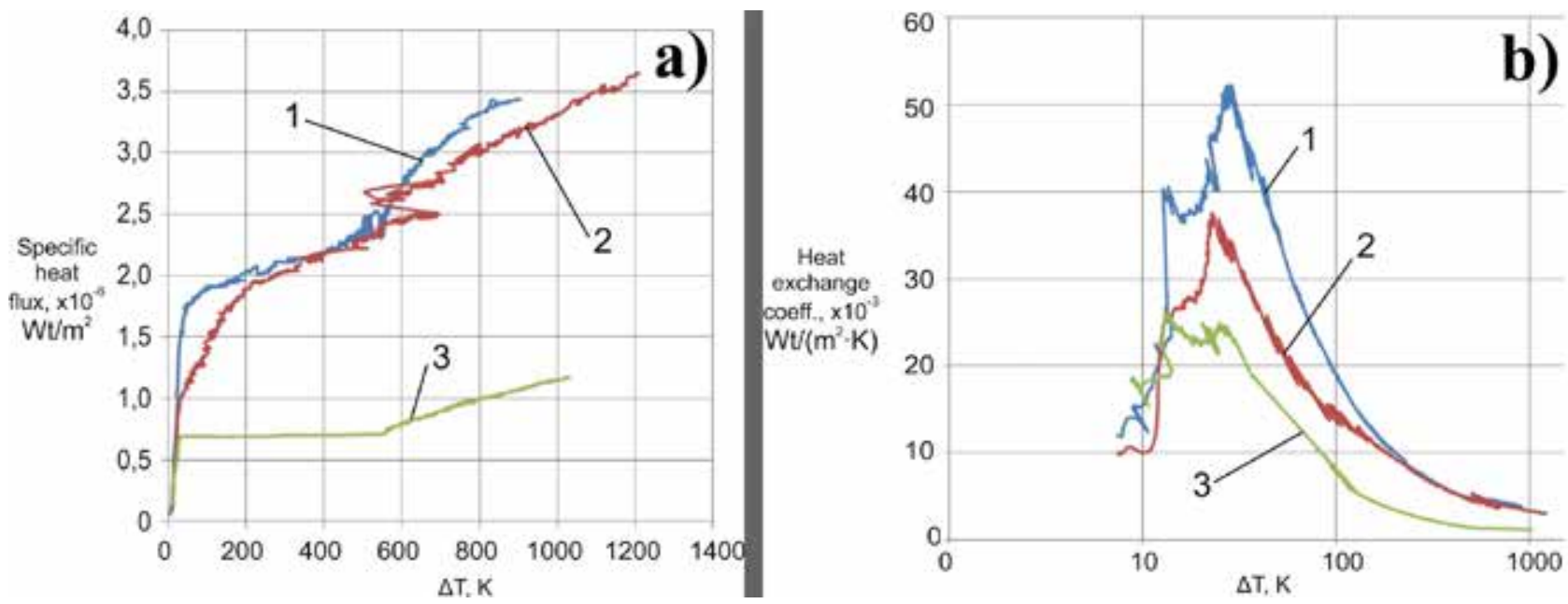

Figure 6. Boiling curves (a) and heat exchange coefficient as a function of surface superheat value ( $\Delta \mathrm{T})$ (b) for nanofluids AlSi-7+CNTs (1), AlSi-7 (2) and distilled water (3)

Figure 4-6 show the boiling curves and the corresponding dependence of the heat transfer coefficient $\alpha$ from the magnitude of superheat $(\Delta \mathrm{T})$ for the studied NFs. The last form various nanostructured architectures on the surface of the heat exchange (Fig. 3.) 
As it can be seen, the character of the surface microrelief and data of porous structure of deposited sediments, shown on Fig. 3 and Table 2, are in the accordance with the value of the heat transfer coefficients, graphs for which are presented on Fig. 4b-6b.

Table 1. Physicochemical characteristics, CHF ( $\left.\mathrm{q}_{\mathrm{cr}}\right)$ and $\alpha_{\max }$ values of some aqueous Nanofluids

\begin{tabular}{|c|c|c|c|c|c|c|c|c|}
\hline $\begin{array}{l}\text { Investigated fluids } \\
\text { on the basis of: }\end{array}$ & $\begin{array}{l}\text { Average } \\
\text { particle } \\
\text { size (nm) }\end{array}$ & $\begin{array}{c}\text { Particle } \\
\text { concentrati } \\
\text { on (mass \%) }\end{array}$ & $\begin{array}{c}\text { Anisometry } \\
\text { coefficient } \\
\mathrm{k}=\mathrm{l} / \mathrm{d}\end{array}$ & $\mathrm{pH}$ & $\begin{array}{c}\text { Surface } \\
\text { tension } \\
\text { at } 20^{\circ} \mathrm{C} \\
\sigma(\mathrm{mN} / \mathrm{m})\end{array}$ & $\begin{array}{l}\text { Electrokineti } \\
\text { c potential, } \\
\zeta(\mathrm{mV})\end{array}$ & $\begin{array}{l}\mathrm{q}_{\mathrm{cr}} \times 10^{-6} \\
\left(\mathrm{~W} / \mathrm{m}^{2}\right)\end{array}$ & $\begin{array}{c}\alpha_{\max } \\
\mathrm{W} / \mathrm{m}^{2} \mathrm{~K}\end{array}$ \\
\hline Distillate water & - & 0 & - & 6.0 & 72.8 & - & 0.7 & 25000 \\
\hline Hydromica (AlSi-6) & $50-400$ & 0.5 & $10-30$ & 5.4 & 72.6 & -25.7 & 1.45 & 25000 \\
\hline $\mathrm{TiO}_{2}$ (rutile) & $70-300$ & 0.5 & $2-5$ & 6.0 & 71.8 & -39.5 & 1.55 & 35000 \\
\hline Attapulgite (AlSi-5) & $100-500$ & 0.5 & $200-400$ & 5.8 & 71.5 & -18.0 & 1.65 & 36000 \\
\hline $\begin{array}{l}\text { Attapulgite + } \\
\text { Montmorillonite } \\
\text { (AlSi-7) }\end{array}$ & $50-500$ & 0.5 & $200-500$ & 5.9 & 72.6 & -19.8 & 2.42 & 38000 \\
\hline $\begin{array}{c}\text { Attapulgite }+ \\
\text { Montmorillonite (1:1) } \\
+ \text { Carbon Nanotube } \\
(0.2 \%) \\
\text { (AlSi-7+CNTs) }\end{array}$ & $70-3000$ & 0.5 & $500-750$ & 6.5 & 71.9 & -11.5 & 3.50 & 52000 \\
\hline
\end{tabular}

Table 2. Adsorption-structural characteristics of nanostructured coatings after nanofluids pool boiling

\begin{tabular}{|c|c|c|c|}
\hline \multirow{2}{*}{ Nanofluids on the basis of: } & \multicolumn{2}{|c|}{ Characteristics of nanostructured coatings } \\
\cline { 2 - 4 } & $\begin{array}{c}\text { Specific surface area, } \\
\mathrm{m}^{2} / \mathrm{g}\end{array}$ & Average micropores radius, nm & Micropores volume $\mathrm{cm}^{3} / \mathrm{g}$ \\
\hline Hydromica & 85,0 & 4.2 & 0.2 \\
\hline Attapulgite + Montmorillonite (1:1) & 375 & 3.0 & 0.54 \\
\hline $\begin{array}{c}\text { Attapulgite + Montmorillonite (1:1) } \\
\text { Carbon Nanotubes (0.2\%) }\end{array}$ & 420 & 2.3 & 0.62 \\
\hline
\end{tabular}

From this comparison it follows that the higher roughness of surface sediments and anisometry of particles, the higher values of $\mathrm{q}_{\mathrm{cr}}$ and $\alpha$ characterizing the intensity of a heat transfer (see Table 1).

However, the experience shows that if even the coefficient of anisometry is high, but the particle shape is flat, as it is typical for particles of hydromica (NF-6), the porosity and roughness of the deposits are low and the thermal parameters at boiling of such NF are low.

Indeed hydromica (Fig. 3a), because of the plate shape of the nanoparticles, forms a close-packed plane layer with a relatively low roughness and weakly expressed porosity compared to other analyzed sediments. Respectively, and the heat transfer coefficient is low: $\alpha_{\max }=25000 \mathrm{~W} / \mathrm{m}^{2} \mathrm{~K}$ (Fig. $4 b)$.

For the NFs on the basis of $\mathrm{TiO}_{2}$ maximum heat transfer coefficient is relatively higher and achieves $35000 \mathrm{~W} / \mathrm{m}^{2} \mathrm{~K}$ (Fig.5b, Table 1). Obviously, this can be explained by the fact that the $\mathrm{TiO}_{2}$ nanoparticles are rounded and form a layer on the heater surface with a larger porosity and roughness (Fig.3b).

Most clearly the effect of porosity and roughness of the sediment on heat transfer reveals for the two NFs: 1) mixture of natural silicates (montmorillonite and attapulgite) AlSi-7 and 2) the same mixture with the addition of carbon nanotubes (AlSi-7 + CNTs). As can be seen from Fig. 3c,d and Table 2, the porosity and roughness of sediments surface, formed at boiling of the second NF, containing CNTs are significantly more noticeable than after boiling of the first NF.

In this case, the heat transfer coefficients $\left(\alpha_{\max }\right)$ for the last two NFs presented on Fig. 6b significantly differ from similar coefficients for hydromica and $\mathrm{TiO}_{2} \mathrm{NFs}$ (Fig.3b,4b): $\alpha_{\max }=38000$ and $52000 \mathrm{~W} / \mathrm{m}^{2} \mathrm{~K}$, correspondingly. Such a large numeric value of heat transfer coefficients and their difference are explained by the high hydrophilicity of aluminosilicate NPs and their crystallochemical nature (second mixture). In addition, it is associated with different form (flat, needle, fibrous), and anisometry of NPs, giving nanostructured sediments with the most developed surface porosity and roughness at NFs boiling (Fig.3d).

Obviously, these are the main three factors that maximize the density of the centers of vaporization, and as a consequence, determine the highest values of heat transfer coefficients $\left(\alpha_{\max }\right)$ and $\operatorname{SHF}\left(\mathrm{q}_{\mathrm{sp}}\right)$.

Indeed, the value of specific heat flux $\left(\mathrm{q}, \mathrm{W} / \mathrm{m}^{2}\right)$ at boiling (both for common fluids and nanofluids) depends on the thermo-physical properties of the liquid and vapor $\left(\rho_{f}, C p, h_{v}\right.$, $\rho_{v}$ ) and internal characteristics of the boiling process. The latter include the bubble departure frequency $(f)$, the density of vaporization centers $(N)$ and departure diameter of vapor bubbles $(D)$, which determines the volume of "separation" bubble $(V)$.

Based on the mechanism described in the physical model 
of boiling [31], the value of the critical heat flux $q_{c r}$ is associated at fluids boiling with the nucleation site density $\left(N, 1 / \mathrm{m}^{2}\right)$ by the following relationship:

$$
\mathrm{q}_{\mathrm{cr}}=\mathrm{N} \cdot \mathrm{V} \cdot \mathrm{f} \cdot\left[\beta \cdot \rho_{\mathrm{f}} \cdot \mathrm{C}_{\mathrm{p}}\left(\mathrm{T}_{\mathrm{v}}-\mathrm{T}_{\infty}\right)+\mathrm{h}_{\mathrm{v}} \cdot \rho_{\mathrm{v}}\right]
$$

where $\beta$ is the ratio of displaced fluid to volume of the detached bubble; $\rho_{f}$ is the fluid density in the core of the flow, $\mathrm{kg} / \mathrm{m}^{3} ; C_{p}$ is specific heat capacity of fluid at constant pressure, $\mathrm{J} / \mathrm{kg} \cdot \mathrm{K} ; T v$ and $T \infty$ are the average temperatures of the fluid volume transported in the flow core by detached bubbles and in the core of the flow, respectively, $\mathrm{K} ; h_{v}$ is specific heat of vaporization, $\mathrm{J} / \mathrm{kg} ; \rho_{v}$ is the steam density, $\mathrm{kg} / \mathrm{m}^{3}$. Here the values of $q, N, V, f, \beta$ и $T_{v}$ are the statistically averaged ones.

At boiling of nanofluids the density of vaporization centers $(N)$ increases most significantly increasing due to the deposition of the porous layer of nanoparticles on the boiling surface.

The visual observation and data video registration of the nanofluids boiling processes showed that the nanostructured deposits are powerful "generators" of bubbles formation. It is the main reason for the CHF growth in contrast to boiling of single-phase fluids (e.g., water). For single-phase fluids at high specific heat fluxes the heating surface is isolated from the boiling fluid by continuous vapor film and it leads to the boiling crisis and consequently to the destruction of the heater. Thus, the roughness of the porous layer is the dominant factor in increase of specific heat flux.

The main difference of the boiling mechanisms of nanofluids and base fluid (e.g. distilled water, etc.) is related with the presence of nanoparticles in NFs. The presence of these particles doesn't results in significant change of the thermophysical and physico-chemical properties compared with these properties the base fluids (Table. 1). However, their presence affects the state of the heater by changes in roughness and wettability of surface and in internal characteristics of boiling process (such as $N, D, f, T v$ and $T \infty$ ). The video registration data of the boiling process evidenced the increasing of $N$ and $f$ values and decreasing of $D$ value. In addition, the decreases of temperatures both at the boundary layer of nanofluids and at the heating surface were recorded. It indicates the beginning of vaporization at lower superheat values of heater surface at nanofluids boiling, compared with the single-component based fluids. It evidence that the start of vaporization can be observed at lower superheating of the heater surface for nanofluids than for the corresponding base fluid.

In addition it is very likely that the introduction of carbon nanotubes with higher thermal conductivity reduces the thermal resistance of the deposited layer, contributing to intensification of heat transfer in the course of NFs boiling.

Comparison of presented boiling curves (Fig. 4a, 5a, 6a) allow to make the conclusion about significant differences in specific heat flux for NFs which form at boiling different roughness of a sediment. So, at the same temperature difference between the heating surface and the temperature of the boiling liquid $(\Delta \mathrm{T}=100 \mathrm{~K})$ specific heat flux $\left(\mathrm{q}_{\mathrm{sp}}\right)$ for different NFs had the following values $\left(\mathrm{MW} / \mathrm{m}^{2}\right)$ : water - 0,7; hydromica - 1,0; $\mathrm{TiO}_{2}$ - 1,4; AlSi7 - 1,5; AlSi7+CNTs - 1,8.

Thus, it is established that presented experimentally obtained values of thermal parameters at NFs boiling are well correlated with porosity and roughness of deposited nanostructures, depending on the shape and the anisometry coefficient of NPs. Consequently, it makes sense for heat intensification to use NFs, which form at boiling nanostructural sediments with developed porosity and roughness.

\section{Conclusions}

1. It is found that the deposition of particles and formation of nanostructures on the heating surface have been observed at the pre-crisis range of the nucleate boiling of water NFs $\left(\mathrm{q}_{\mathrm{cr}}<0.7 \mathrm{MW} / \mathrm{m}^{2}\right)$.

2. It is established that the type of electric current (AC or DC) significantly influence on the structure of the sediment, which is formed on the heater surface during NFs boiling and as a result the thermal parameters of aluminosilicate NFs.

3. The architecture of the forming nanostructures (their topography and roughness) is determined by the shape and anisometry of nanoparticles. The architecture remains almost unchanged up to the temperatures which correspond to the beginning of the change of the NPs crystal structure.

4. The significant correlation between porosity of deposited sediment and thermal parameters of NFs boiling was established. That is, with increasing of a specific surface area and pore volume of sediment the rate of heat flow and the intensity of heat transfer at NFs boiling increase.

5. Maximum heat transfer characteristics of NF boiling $\left(\mathrm{q}_{\mathrm{sp}}\right.$ и $\alpha$ ) were registered in the case of NFs with a mixture of NPs with different anisometry and morphology, giving during boiling nanostructures with the most developed surface porosity and roughness. Most probably, this is due to the most high density centers of vaporization and heat-exchange area in these surface formed nanostructures.

\section{Acknowledgments}

This study was supported by the National Academy of Sciences of Ukraine (Fundamental research program of NASU "Fundamental problems of nanostructured systems, nanomaterials, nanotechnology; Grant \# 24)

\section{REFERENCES}

[1] B.I. Bondarenko, V.N. Moraru, S.V. Sydorenko, D.V. Komysh, A.I. Khovavko, A.V. Snigur. Some peculiarities of heat exchange at pool boiling of aluminosilicates-water based nanofluids, Proceedings of the $8^{\text {th }}$ International Symposium 
on Heat Transfer, October 21-24, 2012, Tsinghua University, Beijing, China, ISHT8-04-05, 181-190, 2012.

[2] B.I. Bondarenko, V.N. Moraru, S.V. Sydorenko, D.V. Komysh, A.I. Khovavko. Nanofluids for energetics: Effect of stabilization on the critical heat flux at boiling, Technical Physics Letters, Vol. 38, No. 9, 853-857, 2012.

[3] B.I. Bondarenko, V.N. Moraru, B.K. Ilienko, A.I. Khovavko, D.V. Komysh, E M. Panov, S.V. Sydorenko, O.V. Snigur. Study of a heat transfer mechanism and critical heat flux at nanofluids boiling, International Journal of Energy for a Clean Environment, Vol. 14, No.2-3, 151-168, 2013.

[4] S.G. Kandlikar. A Theoretical Model to Predict Pool Boiling CHF Incorporating Effects of Contact Angle and Orientation. Journal of Heat Transfer-Transactions ASME, Vol. 123, 1071-1079, 2001.

[5] A. Adamson. Physical chemistry of surfaces, Mir, Moscow, 1979.

[6] Yen-Wen Lu, Satish G. Kandlikar. Nanoscale Surface Modification Techniques for Pool Boiling Enhancement - A Critical Review and Future Directions, Heat Transfer Engineering Vol. 32, 827-842, 2011.

[7] S.J. Kim, I.C. Bang, J. Buongiorno, L.W. Hu. Effects of nanoparticle deposition on surface wettability influencing boiling heat transfer in nanofluids, Applied Physics Letters, Vol.89, 153107 (1-3), 2006.

[8] S.J. Kim, I.C. Bang, J. Buongiorno, L.W. Hu. Study of Pool Boiling and Critical Heat flux Enhancement in Nanofluids, Bulletin Polish Academy of Sciences, Technical Sciences, Vol. 55, 211-216, 2007.

[9] S.J. Kim, I.C. Bang, J. Buongiorno, L.W. Hu. Surface Wettability Change During Pool Boiling of Nanofluids and Its Effect on Critical Heat Flux, International Journal of Heat and Mass Transfer, Vol. 50, 4105-4116, 2007.

[10] T.G. Theofanus et al. The boiling crisis phenomenon. Part II: dryout dynamics and burnout, Experimental Thermal and Fluid Science, Vol.26, 793-810, 2002.

[11] Q.T. Pham, T.I. Kim, S.S. Lee, S.H. Chang. Enhancement of critical heat flux using nano-fluids for Invessel Retention-External Vessel Cooling, Applied Thermal Engineering, Vol. 35, 157-165, 2012.

[12] G. Son, V.K. Dhir, N. Ramanujapu, Dynamics and Heat Transfer Associated With a Single Bubble During Nucleate Boiling on a Horizontal Surface, Journal of Heat Transfer-Transactions ASME, Vol. 121, 623-631, 1999.

[13] C.W. Nan, R. Birringer, D.R. Clarke, H. Gleiter. Effective thermal conductivity of particulate composites with interfacial thermal resistance, Journal of Applied Physics, Vol. 81, 6692-6699, 1997.

[14] J.A. Eastman, S.U.S. Choi, S. Li, W. Yu, L.J. Thompson. Anomalously increased effective thermal conductivities of ethylene glycol-based nanofluids containing copper nanoparticles, Applied Physics Letters, Vol. 78, 718-720, 2001.

[15] P. Keblinski, S.R. Phillpot, S.U.S. Choi, J.A. Eastman. Mechanisms of heat flow in suspensions of nano-sized particles (nanofluids), International Journal of Heat and Mass
Transfer, Vol. 45, 855-863, 2002.

[16] W. Yu, D.M. France, J.L. Routbort, S.U.S. Choi. Review and comparison of nanofluid thermal conductivity and heat transfer enhancements, Heat Transfer Engineering, Vol.29, 432-460, 2008.

[17] S.K. Das, N. Putra, W. Roetzel. Pool Boiling Characteristics of Nano-Fluids, International Journal of Heat and Mass Transfer, Vol. 46, 851-862, 2003.

[18] D. Milanova, R. Kumar. Role of Ions in Pool Boiling Heat Transfer of Pure and Silica Nanofluids, Applied Physics Letters, Vol. 87, 233107 (1-3), 2005.

[19] I.C. Bang, S.H. Chang. Boiling Heat Transfer Performance and Phenomena of $\mathrm{Al}_{2} \mathrm{O}_{3}$-water NanoFluids from a Plain Surface in a Pool, International Journal of Heat and Mass Transfer, Vol. 48, 2407-2419, 2005.

[20] B. Jo, P.S. Jeon, J. Yoo, H.J. Kim. Wide Range Parametric Study for the Pool Boiling of Nano-Fluids With a Circular Plate Heater, Journal of Visualization, Vol. 12, 37-46, 2009.

[21] I.F. Efremov. Periodic colloid structures. - In: Surface and Colloid Science /Ed. By E. Matijevic/. Wiley, New York, Vol.8, ch.2, 3-191, 1975.

[22] Yu. F. Deynegha, Z.R. Ulberg, V.R. Estrela-Liopys. Electrophoretic precipitation of metalopolymers. Naukova dumka, Kiev, 1976 (in Russian).

[23] V.P. Schulman, Yu. F. Deynegha, R.G. Brodkin et al. Electrorheologic effect. Nauka i technika, Minsk, 1972 (in Russian).

[24] S.S. Dukhin, V.N. Shilow. Induced dipole moment and the nonequilibrium double layer of a colloid particle. Advance Colloid and Interface Science, Vol. 13(1), 153-195, 1980.

[25] S.S. Dukhin. Electroconductivity and electrokinetic properties of disperse systems. Naukova dumka, Kiev, 1975 (in Russian).

[26] S.S. Dukhin, V.R. Estrela-Liopys, E.K. Jolkhovsky. Electrosurface phenomena and electrofiltration. Naukova dumka, Kiev, 1985 (in Russian).

[27] V.V. Yagov. Is a crisis in pool boiling actually a hydrodynamic phenomenon? Proceedings of the $8^{\text {th }}$ International Symposium on Heat Transfer, October 21-24, 2012, Tsinghua University, Beijing, China, ISHT8-P7, 2012.

[28] Satish G. Kandlikar, Mark E. Steinke. Contact angles and interface behavior during rapid evaporation of liquid on a heated surface, International Journal of Heat and Mass Transfer, Vol. 45, 3771-3780, 2002.

[29] S.S. Kutateladze. Fundamentals of heat exchange theory. 5-th publ., Atomizdat, Moscow, 1979.

[30] Eric Nolan, Russell Rioux, Pei-Xue Jiang, G. P. Peterson, Calvin Hong Li. Experimental study of contact angle and active nuleation site distribution on nanostructure modified copper surface in pool boiling heat transfer enhancement, Heat Transfer Research, Vol. 44 (1), 115-131, 2013.

[31] M.I. Pavlishchev et al. Investigation of boiling centers density at liquid boiling in unlimited environment. Digest of Chemical Engineering, No. 19, 43-48, Technique, Kiev, 1974 (in Russian). 